\title{
Attitudes Towards Chiropractic: A Repeated Cross- Sectional Survey of Canadian Family Physicians
}

Jason Walter Busse ( $\sim$ bussejw@mcmaster.ca )

McMaster University

Sushmitha Pallapothu

McMaster University

Brian Vinh

McMaster University

Vivienne Lee

McMaster University

Lina Abril

McMaster University

Albana Canga

Institute for Work \& Health

John Riva

McMaster University

Daniel Viggiani

University of Waterloo

Marc Dilauro

McMaster University

Marie-Pierre Harvey

Université du Québec à Trois-Rivières

Isabelle Pagé

Université du Québec à Trois-Rivières

Avneet Bhela

McMaster University

Serena Sandhu

McMaster University

Oluwatoni Makanjuola

McMaster University

Muhammad Taaha Hassan

McMaster University

Ainsley Moore

McMaster University

Claude Gauthier

Private practice 


\section{David Price}

McMaster University

\section{Research Article}

Keywords: physicians, chiropractic, attitude of health personnel, survey

Posted Date: February 19th, 2021

DOI: https://doi.org/10.21203/rs.3.rs-213123/v1

License: () (7) This work is licensed under a Creative Commons Attribution 4.0 International License. Read

Full License 


\section{Abstract}

Background: Attitudes of Canadian family physicians towards chiropractic are uncertain.

Methods: A 50-item survey administered to a ranmdom sample of Canadian family physcians in 2010 , and again in 2019, that inquired about demographic variables, knowledge and use of chiropractic. Imbedded in our survey was an 80-point chiropractic attitude questionnaire (CAQ); higher scores indicated more positive attitudes toward chiropractic.

Results: Among eligible physicians, 251 of 685 in 2010 (37\% response rate) and 162 of 2,429 in 2019 (7\% response rate) provided a completed survey. Approximately half of respondents $(48 \%)$ endorsed a positive impression of chiropractic, with $27 \%$ expressing uncertainty and $25 \%$ holding negative views. Most respondents $(72 \%)$ referred patients for chiropractic care, mainly due to patient request or lack of response to medical care. Most physicians believed that chiropractors provide effective therapy for some musculoskeletal complaints (84\%) and disagreed that chiropractic care was beneficial for non-musculoskeletal conditions (77\%). The majority agreed that chiropractic care was a useful supplement to conventional care (65\%) but most respondents (59\%) also indicated that practice diversity within the chiropractic profession presented a barrier to interprofessional collaboration.

In our adjusted regression model, attitudes towards chiropractic showed trivial improvement from 2010 to 2019 (0.31 points on the $\mathrm{CAQ} ; 95 \% \mathrm{Cl} 0.001$ to 0.62 ). More negative attitudes were associated with older age (-1.55 points for each 10-year increment from age $28 ; 95 \% \mathrm{Cl}-2.67$ to -0.44$)$, belief that adverse events are common with chiropractic care ( -1.41 points; $95 \% \mathrm{Cl}-2.59$ to -0.23$)$ and reported use of the research literature $(-6.04$ points; $95 \% \mathrm{Cl}-8.47$ to -3.61$)$ or medical school ( -5.03 points; $95 \% \mathrm{Cl}=-7.89$ to -2.18$)$ as a source of knowledge on chiropractic. More positive attitudes were associated with endorsing a relationship with a specific chiropractor ( 5.24 points; $95 \% \mathrm{Cl} 2.85$ to 7.64 ), family and friends ( 4.06 points; $95 \% \mathrm{Cl} 1.53$ to 6.60 ), or personal treatment experience ( 4.63 points; $95 \% \mathrm{Cl} 2.14$ to 7.11$)$ as sources of information regarding chiropractic.

Conclusions: Although generally positive, Canadian family physicians' attitudes towards chiropractic are diverse, and most physicians acknowledge that practice diversity within the chiropractic profession presents a barrier to interprofessional collaboration.

\section{Background}

One in eight Canadians report attending a chiropractor in the past year, primarily for low back or neck pain, ${ }^{1,2}$ and many patients receive care from both a family physician and a chiropractor during the course of their complaint ${ }^{3}$. Medicine and chiropractic, however, have a contentious history. ${ }^{4}$ In 1972 the Canadian Medical Association reaffirmed its policy that physicians may not make referrals to chiropractors or acquire $\mathrm{x}$-rays on behalf of chiropractors, ${ }^{5}$ and until 1983 the American Medical Association held that it was unethical for medical doctors to associate with chiropractors ${ }^{6}$. Current interprofessional relationships between family physicians and chiropractors remain suboptimal. ${ }^{7,8}$ 
Chiropractic in Canada exists on a spectrum. While most providers focus on management of musculoskeletal complaints, approximately $19 \%$ of Canadian chiropractors adhere to vitalist traditions of chiropractic which maintain that malpositioned spinal vertebrae (subluxations) interfere with the nervous system causing disease. ${ }^{9}$ Vitalist practitioners in Canada are more likely to hold anti-vaccination beliefs, less likely to adhere to guideline recommendations for use of radiographic imaging, ${ }^{9}$ and receive fewer referrals from physicians

10 . This schism within the profession has been longstanding, ${ }^{11}$ and some opinion leaders have argued for formally dividing the chiropractic profession into evidence-based and vitalist factions ${ }^{12}$.

Many patients do not reveal their use of chiropractic to their primary care physician, in part over concerns of disapproval. ${ }^{13}$ When patients do report receipt of chiropractic care, communication between physicians and chiropractors is often poor. ${ }^{14}$ Understanding how family physicians view chiropractic may provide opportunities to enhance interprofessional relations and improve patient care. The aim of the current study was to survey the attitudes of Canadian family physicians towards chiropractic and re-administer the same survey a decade later to explore for changes in attitudes.

\section{Methods}

\section{Questionnaire development}

With the assistance of epidemiologists and content experts, and reference to the previous literature, ${ }^{15-19}$ we developed a 50-item, English and French-language questionnaire to examine family physicians' attitudes towards chiropractic (Appendix 1). The final questionnaire framed response options with a 5-point Likert scale (strongly agree, agree, undecided, disagree, strongly disagree) as a previous report has shown that closed-ended questions result in fewer incomplete questionnaires than open-ended formats. ${ }^{20}$

We pre-tested the final questionnaire on a group of three family physicians, one with formal training in epidemiology, to evaluate if the questionnaire adequately measured attitudes towards chiropractic, and if the individual questions adequately reflected the domains of formation of attitudes, referral practices, and impressions towards chiropractic. The pretest participants also commented on the clarity and comprehensiveness of the questionnaire.

Thirty survey questions requested demographic data from respondents and asked about their knowledge of chiropractic and referral practices for chiropractic care. The survey also included a 20-item chiropractic attitude questionnaire (CAQ). Each of the 20 questions comprising the CAQ was graded on a 5-point Likert scale (strongly agree, agree, undecided, disagree, strongly disagree), from 0 to 4 . After re-coding so that all reply options were qualitatively in the same direction, the responses were summed to arrive at a total score ranging from 0 (most negative attitude towards chiropractic) to 80 (most positive attitude towards chiropractic). The internal consistency of the CAQ, using all respondents, was high (Cronbach's alpha, 0.83). The last item of the CAQ asked about the respondent's general attitude towards chiropractic and served as an embedded validation question. The Spearman correlation between responses to that question and the total CAQ score (excluding the last question) was $0.85(p<0.01)$, further supporting construct validity of the CAQ. 
We used the 2009 Scott's Canadian Medical Directory ${ }^{21}$ to acquire a random sample of 1,000 Canadian family physicians with a random-number generator. Between October and December 2010, all physicians' offices were called to confirm if they were in active practice, confirm a working fax number, and inquire if an English or French-language survey was preferred. Eligible physicians (those in active practice and for whom a working fax number was identified) were sent a survey by fax. Recipients were provided with a disclosure letter detailing the intent of the survey and explicit instructions that, should they choose not to complete the survey, they could provide this decision by fax or email to avoid further requests. Therefore, informed consent was implied if the questions were answered by the participants. At 4 and 8 weeks following the initial survey, we re-faxed the questionnaire to all non-responders unless they indicated they did not wish to participate. We telephoned each office that received a 3rd (final) survey prior to faxing to encourage completion of the instrument, which has been shown to improve response rates. ${ }^{22}$ Our survey was performed in accordance with the Declaration of Helsinki and approved by the Hamilton Integrated Research Ethics Board (project no. 10-305).

We then used the 2019 Scott's Canadian Medical Directory ${ }^{21}$ to acquire a random sample of 2,996 Canadian family physicians selected using a computer-based random number generator. From September to November 2019, we administered the same 50-item survey to physicians in this sample who were in active practice and for whom we confirmed a working fax number, in the same manner as in 2010. The Hamilton Integrated Research Ethics Board granted approval for re-administration of our survey (project no. 7355).

\section{Statistical analysis}

We generated frequencies for all collected data and, for purposes of presentation, collapsed responses to individual CAQ items into agree (strongly agree + agree), undecided, and disagree (strongly disagree + disagree). We reported categorical data as proportions and continuous data as means and standard deviations (SDs) if normally distributed and as medians and interquartile ranges (IQRs) if not. We identified any individual question within the CAQ in which the proportion of respondents who agreed or disagreed changed by $\geq 10 \%$ between the 2010 and 2019 survey administrations and used an independent samples Mann-Whitney U test to explore for statistical significance.

Based on previous surveys, ${ }^{23-25}$ we hypothesized, a priori, the following associations of respondents' attitudes towards chiropractic: (1) older physicians would hold more negative attitudes; (2) more positive attitudes if they saw a greater proportion of patients with musculoskeletal complaints; (3) physician's endorsing patient feedback, a relationship with a specific chiropractor, personal treatment experience, or feedback from family and friends as sources of information on chiropractic would hold more positive attitudes; and (3) physician's endorsing the scientific literature, professors, the media, or lectures during medical school as sources of information on chiropractic would hold more negative attitudes. We also hypothesized that the re-administration of the survey in 2019 would show more positive attitudes versus the original administration in 2010. These variables were entered into a generalized linear model. The dependent variable, attitude towards chiropractic, was defined as the aggregate score of the CAQ. We calculated that we would require at least 110 completed surveys in order to ensure that our regression model was reliable (10 respondents for each independent variable considered). ${ }^{26}$ 
All comparisons were 2-tailed and an independent factor was considered statistically significant if it had a pvalue $<0.05$ in the final multivariable model. We report the unstandardized regression coefficient and $95 \%$ confidence interval $(\mathrm{Cl})$ for each variable in our regression model. The value of the unstandardized regression coefficient represents the change in response score on the CAQ. Multicollinearity was deemed concerning if the variance inflation factor for any independent variable was greater than five. ${ }^{27}$ We performed all analyses using IBM SPSS 26.0 statistical software (Armonk, NY: IBM Corp).

\section{Results}

\section{Characteristics of respondents}

In 2010, among 685 of 1,000 family physicians who were in active practice and for whom we confirmed a working fax number and sent our survey, 251 returned a completed questionnaire (37\% response rate; Appendix Fig. 1). Among 2,429 eligible family physicians identified in 2019, 162 provided a completed survey for a $7 \%$ response rate (Appendix Fig. 2).

The mean age of respondents was 50 (SD 10) and $56 \%$ were men, although there was a higher prevalence of women in the more recent survey (40\% in 2010 and $49 \%$ in 2019). Most respondents had been active clinically for $>20$ years and worked in a community-based practice focused on general family medicine. Most physicians attended to patient populations of which $>30 \%$ presented with musculoskeletal complaints. (Table 1) 
Table 1

Demographic characteristics of respondents

\begin{tabular}{|c|c|c|}
\hline Year of administration & 2010 & 2019 \\
\hline No. of respondents & 251 & 162 \\
\hline Age, mean (SD) & $51(10)$ & $50(10)$ \\
\hline Gender, n (\%) 1 & $150(60 \%)$ & $80(51 \%)$ \\
\hline $\begin{array}{l}\text { Male } \\
\text { Female }\end{array}$ & $101(40 \%)$ & 77 (49\%) \\
\hline Years in practice, n (\%) & $19(8 \%)$ & $14(9 \%)$ \\
\hline$<5$ years & $34(14 \%)$ & $25(15 \%)$ \\
\hline 5 to 10 years & $50(20 \%)$ & $36(22 \%)$ \\
\hline $\begin{array}{l}11 \text { to } 20 \text { years } \\
>20 \text { years }\end{array}$ & $148(59 \%)$ & $87(54 \%)$ \\
\hline Country of origin, $n(\%)^{2}$ & $193(78 \%)$ & $104(67 \%)$ \\
\hline Canada & $6(2 \%)$ & $2(1 \%)$ \\
\hline United States & $49(20 \%)$ & $50(32 \%)$ \\
\hline Other & & \\
\hline
\end{tabular}

1 total number of respondents was 157 for the 2019 survey

2 total number of respondents was 156 for the 2019 survey

${ }^{3}$ total number of respondents was 249 for the 2010 survey

4 total percentage is $>100 \%$ as respondents could choose more than one option 


\begin{tabular}{|c|c|c|}
\hline Year of administration & 2010 & 2019 \\
\hline Practice environment, $\mathrm{n}(\%)^{3}$ & $153(61 \%)$ & $116(72 \%)$ \\
\hline Community & $130(52 \%)$ & $55(34 \%)$ \\
\hline Private practice & $55(22 \%)$ & $47(29 \%)$ \\
\hline Hospital-based & $45(18 \%)$ & $32(20 \%)$ \\
\hline Multidisciplinary & $31(12 \%)$ & $16(10 \%)$ \\
\hline \multicolumn{3}{|l|}{ Academic } \\
\hline Patient population with musculoskeletal complaints, n (\%) 4 & $5(2 \%)$ & $26(16 \%)$ \\
\hline$<10 \%$ & 46 (19\%) & $41(25 \%)$ \\
\hline $10-20 \%$ & $71(29 \%)$ & $34(21 \%)$ \\
\hline $21-30 \%$ & $59(24 \%)$ & $29(18 \%)$ \\
\hline $31-40 \%$ & $58(23 \%)$ & $52(32 \%)$ \\
\hline $41-70 \%$ & $10(4 \%)$ & $7(3 \%)$ \\
\hline \multicolumn{3}{|l|}{$>70 \%$} \\
\hline \multicolumn{3}{|l|}{1 total number of respondents was 157 for the 2019 survey } \\
\hline \multicolumn{3}{|l|}{2 total number of respondents was 156 for the 2019 survey } \\
\hline \multicolumn{3}{|l|}{3 total number of respondents was 249 for the 2010 survey } \\
\hline 4 total percentage is $>100 \%$ as respondents could choose $\mathrm{m}$ & at & tion \\
\hline
\end{tabular}




\begin{tabular}{|lll|}
\hline Year of administration & $\mathbf{2 0 1 0}$ & $\mathbf{2 0 1 9}$ \\
\hline Clinical area, $\mathrm{n}(\%){ }^{4}$ & $236(94 \%)$ & $145(90 \%)$ \\
General family & $52(21 \%)$ & $29(18 \%)$ \\
Geriatrics & $48(19 \%)$ & $19(12 \%)$ \\
Pediatrics & $45(18 \%)$ & $32(20 \%)$ \\
Palliative care & $44(18 \%)$ & $39(24 \%)$ \\
Emergency medicine & $39(16 \%)$ & $22(14 \%)$ \\
\hline Obstetrics \& gynecology & $38(15 \%)$ & $13(8 \%)$ \\
\hline Psychotherapy & $34(14 \%)$ & $24(15 \%)$ \\
\hline Pain medicine & $33(13 \%)$ & $16(10 \%)$ \\
\hline Sports medicine & $14(6 \%)$ & $5(3 \%)$ \\
\hline Occupational medicine & $7(3 \%)$ & $4(3 \%)$ \\
\hline Anesthesia & & \\
\hline 1 total number of respondents was 157 for the 2019 survey & & \\
\hline 2 total number of respondents was 156 for the 2019 survey & & \\
\hline${ }^{3}$ total number of respondents was 249 for the 2010 survey & & \\
\hline 4 total percentage is $>$ 100\% as respondents could choose more than one option
\end{tabular}

Respondents endorsed multiple sources of information regarding chiropractic, but feedback from their patients was the most common. Seventy-one percent of family physicians reported referring patients for chiropractic care, and most referred $\leq 25$ patients per year. Referrals were usually prompted by patient request $(57 \% ; 237$ of 413$)$ or non-response to medical treatment $(40 \% ; 166$ of 413$)$. (Table 2$)$ 
Table 2

Family physician's sources of information on chiropractic and referral practices

\begin{tabular}{|lll|}
\hline Year of administration & 2010 & 2019 \\
\hline No. of respondents & 251 & 162 \\
\hline Sources of information on chiropractic, $\mathrm{n}(\%)^{1}$ & $210(84 \%)$ & $121(75 \%)$ \\
Patient feedback & $105(42 \%)$ & $51(32 \%)$ \\
Relationship with a specific chiropractor & $94(38 \%)$ & $67(41 \%)$ \\
Research literature & $85(34 \%)$ & $66(41 \%)$ \\
Personal treatment experience & $79(32 \%)$ & $48(30 \%)$ \\
Family and friends & $50(20 \%)$ & $39(24 \%)$ \\
Medical school & $44(18 \%)$ & $21(13 \%)$ \\
Media & $43(17 \%)$ & $29(18 \%)$ \\
Professors/supervisors/mentors & $11(4 \%)$ & $10(6 \%)$ \\
Residency & & \\
\hline Frequency of patient referral for chiropractic treatment, $\mathrm{n}(\%){ }^{2}$ & $3(1 \%)$ & $1(1 \%)$ \\
Daily & $46(18 \%)$ & $26(17 \%)$ \\
Weekly & $79(32 \%)$ & $51(33 \%)$ \\
Monthly & $56(22 \%)$ & $30(19 \%)$ \\
Every year & $67(27 \%)$ & $49(31 \%)$ \\
Never & & \\
Number of patients referred for chiropractic care per year, $\mathrm{n}(\%)^{3}$ & $86(34 \%)$ & $57(36 \%)$ \\
1 to 10 & $52(21 \%)$ & $34(21 \%)$ \\
11 to 25 & $32(13 \%)$ & $17(11 \%)$ \\
26 to 50 & $14(6 \%)$ & $10(6 \%)$ \\
$>50$ & $67(27 \%)$ & $42(26 \%)$ \\
None & & \\
& & \\
\hline
\end{tabular}

\begin{tabular}{|l|}
\hline 1 total percentage is $>100 \%$ as respondents could choose more than one option \\
\hline 2 total number of respondents was 157 for the 2019 survey \\
\hline${ }^{3}$ total number of respondents was 169 for the 2019 survey \\
\hline 4 respondents are limited to the family physicians that reported referring patients for chiropractic \\
\hline
\end{tabular}




\begin{tabular}{|lll|}
\hline Year of administration & 2010 & 2019 \\
\hline Reason for chiropractic referral, $\mathrm{n}(\%)^{1,4}$ & $140(56 \%)$ & $97(68 \%)$ \\
Patient request & $103(41 \%)$ & $63(44 \%)$ \\
Non-response to medical treatment & $73(29 \%)$ & $41(29 \%)$ \\
& & \\
& & \\
& & \\
& & \\
\hline Literature supports chiropractic care & $29(23 \%)$ & $29(20 \%)$ \\
\hline Relationship with a specific chiropractor & $17(7 \%)$ & $9(6 \%)$ \\
\hline Personal experience as a chiropractic patient & & \\
\hline Other reasons & & \\
\hline${ }^{1}$ total percentage is > 100\% as respondents could choose more than one option & \\
\hline${ }^{2}$ total number of respondents was 157 for the 2019 survey & \\
\hline${ }^{3}$ total number of respondents was 169 for the 2019 survey & \\
\hline${ }^{4}$ respondents are limited to the family physicians that reported referring patients for chiropractic \\
\hline
\end{tabular}

Only $13 \%$ of physicians (53 of 413 ) worked in a multidisciplinary environment where chiropractic care was available, and 40\% (165 of 413) had sought chiropractic care for themselves. Most had not received information on chiropractic during their medical training, and the majority $(80 \%)$ felt their education should $(52 \% ; 214$ of 413$)$ or possibly $(28 \% ; 115$ of 413$)$ include information regarding chiropractic. Most respondents' opinions on chiropractic were formed after medical school (82\%; 337 of 413$)$, and most (51\%; 209 of 413 ) described themselves as a little knowledgeable. In 2010, most respondents (52\%) felt that adverse events were uncommon with chiropractic care, and in 2019 most physicians believed that adverse events were common but serious events were rare (47\%). In 2010, most respondents (46\%) were very comfortable discussing chiropractic with their patients, whereas in 2019 most (41\%) were somewhat comfortable. (Appendix Table 1)

Fifteen percent (62 of 413) of physicians felt that chiropractic care should be available in multidisciplinary settings (29\% were unsure), and $25 \%$ felt that chiropractic should be available in hospitals, either without ( $8 \%$; 34 of 413$)$ or with physician referral (17\%; 69 of 413$)$. Respondents varied on whether chiropractic care should be offset by government funding: $35 \%$ agreed, $33 \%$ were unsure, and $27 \%$ disagreed. Forty-three percent of family physicians definitely $(17 \%)$ or somewhat $(26 \%)$ perceived chiropractors as primary care 
providers, and most ( $81 \% ; 335$ of 413$)$ wanted consultation notes from chiropractors who attended their patients. Seventy-five percent of respondents had received requests from chiropractors to refer patients for imaging studies. Most physicians $(59 \% ; 245$ of 413$)$ believed that practice diversity within the chiropractic profession was a barrier to interprofessional collaboration. (Appendix Table 2)

\section{Attitudes towards chiropractic}

Forty-eight percent of family physicians (198 of 413) endorsed a positive impression of chiropractic, $27 \%$ were unsure, and $25 \%$ held negative views. Respondents endorsing a positive view had an average CAQ score of 50.2 out of 80 (SD 7.5), undecided respondents had an average CAQ score of 39.4 (SD 5.8), and physicians with negative impressions had a mean CAQ score of 24.9 (SD 9.1). An important change in continuous outcome measures can be estimated as half a SD of the aggregate score for a given population, ${ }^{28}$ and by this standard, a 6-point difference on the CAQ would be considered meaningful.

Responses to individual items on the CAQ are provided in Table 3, and there were 5 items in which the proportion of respondents who agreed or disagreed shifted by $\geq 10 \%$ from the administration in 2010 compared to the re-administration in 2019. Canadian family physicians surveyed in 2019 were: (1) more likely to disagree that chiropractors promote unnecessary treatment plans ( $28 \%$ in 2019 vs. $18 \%$ in $2010 ; p<0.001)$, (2) more likely to agree that chiropractors can reduce patient overload for family physicians specific to musculoskeletal complaints ( $58 \%$ vs. $47 \% ; p=0.27)$, (3) more likely to agree that chiropractors provide effective care for post-surgical rehabilitation ( $24 \%$ vs. $14 \% ; p=0.05)$, (4) less likely to agree that chiropractors engage in overly aggressive marketing ( $35 \%$ vs. $43 \% ; p=0.24),(5)$ and more likely to agree that chiropractors treat in accordance with evidence-based practices ( $26 \%$ vs. $14 \%$; $p=0.05)$. 
Table 3

Responses to the chiropractic attitude questionnaire $(n=251$ in 2010; $n=162$ in 2019)

\begin{tabular}{|c|c|c|c|c|c|c|}
\hline \multirow[t]{2}{*}{ Item } & \multicolumn{2}{|c|}{ Agree, n (\%) } & \multicolumn{2}{|c|}{$\begin{array}{l}\text { Undecided, n } \\
\text { (\%) }\end{array}$} & \multicolumn{2}{|c|}{ Disagree, $\mathrm{n}(\%)$} \\
\hline & 2010 & 2019 & 2010 & 2019 & 2010 & 2019 \\
\hline \multirow{2}{*}{$\begin{array}{l}\text { Chiropractors promote unnecessary treatment } \\
\text { plans }\end{array}$} & 121 & 65 & 86 & 52 & 44 & 45 \\
\hline & $(48 \%)$ & $(40 \%)$ & $(34 \%)$ & $(32 \%)$ & $(18 \%)$ & $(28 \%)$ \\
\hline \multirow{2}{*}{$\begin{array}{l}\text { Chiropractors provide effective therapy for some } \\
\text { musculoskeletal conditions }\end{array}$} & 216 & 130 & 20 & 20 & 15 & 12 \\
\hline & $(86 \%)$ & $(80 \%)$ & $(8 \%)$ & $(12 \%)$ & $(6 \%)$ & $(7 \%)$ \\
\hline \multirow{2}{*}{$\begin{array}{l}\text { Chiropractors make excessive use of radiographic } \\
\text { imaging }\end{array}$} & 83 & 58 & 107 & 57 & 61 & 47 \\
\hline & $(33 \%)$ & $(36 \%)$ & $(43 \%)$ & $(35 \%)$ & $(24 \%)$ & $(29 \%)$ \\
\hline \multirow[t]{2}{*}{ Chiropractors provide a patient centered approach } & 112 & 75 & 111 & 70 & 28 & 17 \\
\hline & $(45 \%)$ & $(46 \%)$ & $(44 \%)$ & $(43 \%)$ & $(11 \%)$ & $(11 \%)$ \\
\hline \multirow{2}{*}{$\begin{array}{l}\text { I have to spend time correcting erroneous } \\
\text { information patients have received from } \\
\text { chiropractors }\end{array}$} & 81 & 53 & 48 & 33 & 122 & 76 \\
\hline & $(32 \%)$ & $(33 \%)$ & $(19 \%)$ & $(20 \%)$ & $(49 \%)$ & $(47 \%)$ \\
\hline \multirow{2}{*}{$\begin{array}{l}\text { Chiropractic manipulation of the neck is generally } \\
\text { a safe therapy }\end{array}$} & 59 & 37 & 70 & 54 & 122 & 71 \\
\hline & $(24 \%)$ & $(23 \%)$ & $(28 \%)$ & $(33 \%)$ & $(49 \%)$ & $(44 \%)$ \\
\hline \multirow{2}{*}{$\begin{array}{l}\text { Chiropractors can provide effective therapy for } \\
\text { some non- musculoskeletal conditions (e.g. } \\
\text { asthma, colic, etc.) }\end{array}$} & 13 & 9 & 37 & 37 & 201 & 116 \\
\hline & $(5 \%)$ & $(6 \%)$ & (15\%) & $(23 \%)$ & $(80 \%)$ & $(72 \%)$ \\
\hline \multirow{2}{*}{$\begin{array}{l}\text { Family physicians may risk professional liability if } \\
\text { they refer a patient to a chiropractor }\end{array}$} & 50 & 36 & 74 & 54 & 127 & 72 \\
\hline & $(20 \%)$ & $(22 \%)$ & $(30 \%)$ & $(33 \%)$ & $(51 \%)$ & $(44 \%)$ \\
\hline \multirow{2}{*}{$\begin{array}{l}\text { Chiropractors can reduce patient overload for } \\
\text { family physicians with respect to patients with } \\
\text { musculoskeletal complaints }\end{array}$} & 119 & 94 & 62 & 34 & 70 & 34 \\
\hline & $(47 \%)$ & $(58 \%)$ & $(25 \%)$ & $(21 \%)$ & $(28 \%)$ & $(21 \%)$ \\
\hline \multirow{2}{*}{$\begin{array}{l}\text { Chiropractors provide patients with } \\
\text { misinformation regarding vaccination }\end{array}$} & 96 & 58 & 120 & 74 & 35 & 30 \\
\hline & $(38 \%)$ & $(36 \%)$ & $(48 \%)$ & $(46 \%)$ & $(14 \%)$ & $(19 \%)$ \\
\hline \multirow{2}{*}{$\begin{array}{l}\text { Chiropractic provides effective therapy for post- } \\
\text { surgical rehabilitation }\end{array}$} & 35 & 38 & 152 & 81 & 64 & 43 \\
\hline & $(14 \%)$ & $(24 \%)$ & $(61 \%)$ & $(50 \%)$ & $(26 \%)$ & $(27 \%)$ \\
\hline \multirow[t]{2}{*}{ Chiropractors lack sufficient clinical training } & 44 & 25 & 110 & 60 & 97 & 77 \\
\hline & $(18 \%)$ & $(15 \%)$ & $(44 \%)$ & $(37 \%)$ & $(39 \%)$ & $(48 \%)$ \\
\hline \multirow{2}{*}{$\begin{array}{l}\text { Chiropractic care is a useful supplement to } \\
\text { conventional medicine }\end{array}$} & 163 & 106 & 55 & 30 & 33 & 26 \\
\hline & $(65 \%)$ & $(65 \%)$ & $(22 \%)$ & $(19 \%)$ & $(13 \%)$ & $(16 \%)$ \\
\hline
\end{tabular}




\begin{tabular}{|c|c|c|c|c|c|c|}
\hline \multirow[t]{2}{*}{ Item } & \multicolumn{2}{|c|}{ Agree, n (\%) } & \multicolumn{2}{|c|}{$\begin{array}{l}\text { Undecided, } n \\
\text { (\%) }\end{array}$} & \multicolumn{2}{|c|}{ Disagree, n (\%) } \\
\hline & 2010 & 2019 & 2010 & 2019 & 2010 & 2019 \\
\hline \multirow{2}{*}{$\begin{array}{l}\text { Chiropractors engage in overly aggressive } \\
\text { marketing }\end{array}$} & 107 & 57 & 95 & 51 & 49 & 54 \\
\hline & $(43 \%)$ & $(35 \%)$ & $(38 \%)$ & (31\%) & $(20 \%)$ & (33\%) \\
\hline \multirow{2}{*}{$\begin{array}{l}\text { Chiropractic includes ideas and methods from } \\
\text { which conventional medicine could benefit }\end{array}$} & 109 & 68 & 84 & 62 & 58 & 32 \\
\hline & $(43 \%)$ & $(42 \%)$ & $(34 \%)$ & $(38 \%)$ & $(23 \%)$ & $(20 \%)$ \\
\hline \multirow{2}{*}{$\begin{array}{l}\text { The results of chiropractic manipulation are due } \\
\text { to the placebo effect }\end{array}$} & 33 & 23 & 89 & 62 & 129 & 77 \\
\hline & $(13 \%)$ & $(14 \%)$ & $(36 \%)$ & $(38 \%)$ & $(51 \%)$ & (48\%) \\
\hline \multirow{2}{*}{$\begin{array}{l}\text { Chiropractors treat in accordance with evidence- } \\
\text { based practices }\end{array}$} & 36 & 42 & 141 & 75 & 74 & 45 \\
\hline & $(14 \%)$ & $(26 \%)$ & $(56 \%)$ & $(46 \%)$ & $(30 \%)$ & (28\%) \\
\hline \multirow{2}{*}{$\begin{array}{l}\text { Chiropractic has no role in the routine care of my } \\
\text { patients }\end{array}$} & 75 & 36 & 43 & 35 & 133 & 91 \\
\hline & $(30 \%)$ & $(22 \%)$ & $(17 \%)$ & $(22 \%)$ & $(53 \%)$ & (56\%) \\
\hline \multirow{2}{*}{$\begin{array}{l}\text { Chiropractic breeds dependency in patients on } \\
\text { short-term symptomatic relief }\end{array}$} & 88 & 55 & 68 & 52 & 95 & 55 \\
\hline & $(35 \%)$ & $(34 \%)$ & $(27 \%)$ & $(32 \%)$ & $(38 \%)$ & (34\%) \\
\hline \multirow[t]{2}{*}{ Overall, my impression of chiropractic is favorable } & 118 & 80 & 68 & 43 & 65 & 39 \\
\hline & $(47 \%)$ & $(49 \%)$ & $(27 \%)$ & $(27 \%)$ & $(26 \%)$ & $(24 \%)$ \\
\hline
\end{tabular}

In our adjusted regression model, overall impressions towards chiropractic showed trivial improvement from 2010 to 2019 ( 0.31 points on the $\mathrm{CAQ} ; 95 \% \mathrm{Cl} 0.001$ to 0.62$)$. More negative attitudes were associated with older age ( -1.55 points for each incremental decade; $95 \% \mathrm{Cl}-2.67$ to -0.44$)$, belief that adverse events are common with chiropractic care $(-1.41$ points; $95 \% \mathrm{Cl}-2.59$ to -0.23$)$ and reported use of the research literature $(-6.04$ points; $95 \% \mathrm{Cl}-8.47$ to -3.61$)$ or medical school $(-5.03$ points; $95 \% \mathrm{Cl}=-7.89$ to -2.18$)$ as a source of knowledge on chiropractic. More positive attitudes were associated with endorsing a relationship with a specific chiropractor ( 5.24 points; $95 \% \mathrm{Cl} 2.85$ to 7.64 ), family and friends ( 4.06 points; $95 \% \mathrm{Cl} 1.53$ to 6.60 ), or personal treatment experience ( 4.63 points; $95 \% \mathrm{Cl} 2.14$ to 7.11 ) as sources of information regarding chiropractic. (Table 4) The variance inflation factor was less than 1.2 for each independent variable, suggesting no issues with multicollinearity. Our model explained approximately $26 \%$ of the variation (adjusted $R^{2}=0.26$ ) in family physician's attitudes toward chiropractic. 
Table 4

Variables associated with family physicians' attitudes towards chiropractic $(n=379)$

\begin{tabular}{|c|c|c|c|c|}
\hline Variable & $\begin{array}{l}\text { Unstandardized } \\
\text { regression coefficient } \\
\text { from univariable } \\
\text { analysis } \\
(95 \% \mathrm{Cl})\end{array}$ & $\begin{array}{l}\mathrm{p}- \\
\text { value }\end{array}$ & $\begin{array}{l}\text { Unstandardized } \\
\text { regression coefficient } \\
\text { from multivariable } \\
\text { analysis } \\
(95 \% \mathrm{Cl})\end{array}$ & $\begin{array}{l}\text { p- } \\
\text { value }\end{array}$ \\
\hline $\begin{array}{l}\text { Year of survey administration } \\
\text { (2019 v. 2010) }\end{array}$ & $0.16(-0.17$ to 0.48$)$ & 0.34 & 0.31 (0.001 to 0.62$)$ & 0.05 \\
\hline $\begin{array}{l}\text { Age (for each 10-year } \\
\text { increment) }\end{array}$ & $-0.75(-1.99$ to 0.49$)$ & 0.24 & $-1.55(-2.67$ to -0.44$)$ & 0.007 \\
\hline $\begin{array}{l}\% \text { of practice dedicated to } \\
\text { musculoskeletal complaints }\end{array}$ & $0.24(-0.51$ to 0.99$)$ & 0.53 & $0.16(-0.51$ to 0.83$)$ & 0.48 \\
\hline $\begin{array}{l}\text { Belief that adverse events are } \\
\text { common with chiropractic care }\end{array}$ & $-1.42(-2.66$ to -0.19$)$ & 0.02 & $-1.41(-2.59$ to -0.23$)$ & 0.02 \\
\hline \multicolumn{5}{|l|}{ Information source for chiropractic * } \\
\hline -Patient feedback & $1.93(-1.24$ to 5.10$)$ & 0.23 & $1.61(-1.29$ to 4.51$)$ & 0.28 \\
\hline \multirow{2}{*}{$\begin{array}{l}\text {-Relationship with a specific } \\
\text { chiropractor }\end{array}$} & 7.74 (5.26 to 10.22$)$ & \multirow{2}{*}{$\dot{0} 001$} & 5.24 (2.85 to 7.64$)$ & \multirow{2}{*}{$<0.001$} \\
\hline & $-7.05(-9.54$ to -4.57$)$ & & $-6.04(-8.47$ to -3.61$)$ & \\
\hline \multirow{3}{*}{$\begin{array}{l}\text {-Research literature } \\
\text {-Personal treatment experience } \\
\text {-Family and friends }\end{array}$} & 8.65 (6.17 to 11.12$)$ & 0.001 & $4.63(2.14$ to 7.11$)$ & $\dot{0} 001$ \\
\hline & 6.50 (3.85 to 9.14$)$ & $<$ & $4.06(1.53$ to 6.60$)$ & $<001$ \\
\hline & $-5.12(-8.41$ to -1.83$)$ & & $-2.23(-5.37$ to 0.92$)$ & \multirow{2}{*}{0.002} \\
\hline \multirow{2}{*}{$\begin{array}{l}\text { Professors/supervisors/mentors } \\
\text {-Media }\end{array}$} & $-4.17(-7.57$ to -0.77$)$ & 0.001 & $-1.39(-4.59$ to 1.82$)$ & \\
\hline & $-5.51(-8.52$ to -2.49$)$ & 0.002 & $-5.03(-7.89$ to -2.18$)$ & 0.11 \\
\hline -Medical school & & $\begin{array}{l}0.02 \\
< \\
0.001\end{array}$ & & 0.001 \\
\hline $95 \% \mathrm{Cl}=95 \%$ confidence interval & & & & \\
\hline
\end{tabular}

\section{Discussion}

Our survey of Canadian family physicians found that most report favorable perceptions of chiropractic, including the belief that chiropractic care is effective for some musculoskeletal complaints, provides a useful complement to conventional medicine, and can reduce family practitioner workload. However, attitudes are diverse, and respondents also highlighted several concerns, including lack of evidence-base care, dependency on short-term symptom relief, and vaccine misinformation. Most physicians formed their opinions on 
chiropractic after medical school, primarily from patients' feedback, and the majority felt medical training should include information on chiropractic. Most referred some patients for chiropractic care each year, typically in response to requests by patients or because they had not responded to medical care.

Most physicians received requests from chiropractors to refer patients for imaging studies, and wanted to receive consultation notes for shared patients, but the majority also agreed that practice diversity in the chiropractic profession presented a barrier to interprofessional collaboration. Canadian family physician's attitudes towards chiropractic have remained similar over the past decade. Negative attitudes toward chiropractic care were associated with older age, belief that adverse events are common with chiropractic care, and reported use of the research literature or medical school as a source of knowledge on chiropractic were associated with more negative attitudes. Endorsing a relationship with a specific chiropractor, family and friends, or personal treatment experience as sources of information regarding chiropractic were associated with more positive attitudes.

\section{Strengths and limitations}

The strengths of our study include random sampling of all Canadian family physicians, and survey design and conduct consistent with best practices ${ }^{29}$. Our assessment of attitudes towards chiropractic was based on the CAQ, which has been validated among other groups of Canadian healthcare providers. ${ }^{23-25}$ Our study does have limitations, including an overall response rate of $13 \%$, which was lower for the re-administration of the survey. Non-responders may have differed systematically from responders, and the generalizability of our findings to family physicians practicing outside of Canada is uncertain. Our model explained $26 \%$ of the variation in respondent's attitudes toward chiropractic, indicating that there remain additional variables of importance that our survey did not capture.

\section{Relevant literature}

In August 2018, the Canadian Chiropractic Association (CCA) published a statement emphasizing a focus on promoting interprofessional collaboration, ${ }^{30}$ and the CCA advocates for integration of chiropractors into interprofessional health teams ${ }^{31}$. We found that although most Canadian family physicians endorse chiropractic care as a useful supplement to conventional medicine, only one in eight physicians reported working with a chiropractor, and practice diversity within the chiropractic profession is perceived as a barrier to interprofessional collaboration.

Most family physicians disagreed that chiropractic care was effective for non-musculoskeletal conditions, and systematic reviews on this topic provide little support to challenge this assertion. ${ }^{32-35}$ Most respondents agreed that chiropractic care is effective for certain musculoskeletal complaints, and spinal manipulation, which is commonly provided by chiropractors, has received support for management of axial complaints from recent systematic reviews ${ }^{36-41}$ and clinical practice guidelines ${ }^{42-44}$. Paradoxically, support from the scientific literature was a common reason given for referral of patients for chiropractic care, while reliance on research literature for information on chiropractic was associated with more negative attitudes. The published literature on chiropractic varies considerably in tone, quality, and findings. Readers of sensationalistically titled case reports (e.g. "Deaths after chiropractic: a review of published cases" ${ }^{45}$ ) are 
likely to form very different impressions versus less eye-catching, but more rigorously conducted studies on the same topic that arrive at different conclusions. ${ }^{46-48}$

Close to half of respondents disagreed that chiropractic manipulation of the cervical spine was generally safe; however, although some observational studies have suggested a rare association with stroke, ${ }^{49-51}$ studies with greater methodologic safeguards against bias have failed to confirm either an association between utilization of chiropractic and risk of stroke, ${ }^{48}$ or an association between chiropractic care and an increased risk of stroke compared to primary care ${ }^{46,47}$. This suggests that associations reported in some studies between chiropractic care and stroke may be due to patients with early dissection-related symptoms seeking care prior to developing their strokes. ${ }^{52-54}$

Musculoskeletal complaints, particularly low back pain, are common complaints in primary care. ${ }^{55}$ Our findings suggest that most Canadian family physicians believe chiropractors can provide effective care for some musculoskeletal complaints; however, many physicians do not believe that chiropractors treat in accordance with evidence-based practices and have concerns regarding the safety of cervical manipulation. The chiropractic profession may help address such concerns by continuing to assess the concordance between evidence and practice ${ }^{56-59}$ and promoting greater standardization of care where important variability exists. Further research on the benefits and harms of cervical manipulation is needed to establish the appropriate role of this modality. ${ }^{60,61}$ Improved patient satisfaction and outcomes are associated with interprofessional collaboration among healthcare providers. ${ }^{62,63}$ Moreover, preliminary evidence suggests that collaboration between chiropractors and physicians for shared patients may reduce use of prescription medication, including opioids, imaging studies, and referrals for surgical consultation. ${ }^{64,65}$ Efforts to improve relations between family physicians and chiropractors may benefit from increased opportunities to work together and learn from each other. ${ }^{66,67}$

\section{Conclusions}

Although generally positive, Canadian family physicians' attitudes towards chiropractic range from very positive to extremely negative, and most physicians acknowledge that practice diversity within the chiropractic profession presents a barrier to interprofessional collaboration. Efforts to improve interprofessional relations could include providing evidence-based information on chiropractic during medical training, and increased opportunities for family physicians and chiropractors to work together and learn from each other.

\section{Declarations}

\section{Ethics approval and consent to participate}

Recipients were provided with a disclosure letter detailing the intent of the survey and explicit instructions that, should they choose not to complete the survey, they could provide this decision by fax or email to avoid further requests. Therefore, informed consent was implied if the questions were answered by the participants. 
The Hamilton Integrated Research Ethics Board granted approval of our survey in 2010 (project no. 10-305), and for re-administration of our survey in 2019 (project no. 7355).

\section{Consent for publication}

Not applicable.

\section{Availability of data and materials}

The blinded study data can be obtained from the corresponding author at: bussejw@mcmaster.ca

\section{Competing interests}

The authors declare that they have no competing interests.

\section{Funding}

Our 2010 survey was supported by a $\$ 2,500$ research grant from the Ontario Chiropractic Association. The funding source had no role in the conduct of the study; the collection, management, analysis, or interpretation of the data; or the preparation or approval of the manuscript. We have no other conflicts of interest to declare.

\section{Authors' contributions}

JWB conceived and designed the study. SP, BV, VL, LA, AC, JJR, DV, MD, AB, SS, OM and MH called physicians offices and administered surveys. JWB carried out the statistical analysis. J. Busse, SP, BV, JJR, M-PH, IP, AM, CAG and DJP interpreted the data. JWB drafted the manuscript. All authors critically revised the article for important intellectual content and gave final approval for the article. The corresponding author attests that all listed authors meet authorship criteria.

\section{Acknowledgements}

Not applicable.

\section{References}

1. Beliveau PJH, Wong JJ, Sutton DA, et al. The chiropractic profession: a scoping review of utilization rates, reasons for seeking care, patient profiles, and care provided. Chiropr Man Therap 2017; 25:35.

2. Lawrence DJ, Meeker WC. Chiropractic and CAM utilization: a descriptive review. Chiropr Osteopat. 2007; 15: 2. 
3. Bath B, Lawson J, Ma D. et al. Self-reported use of family physician, chiropractor and physiotherapy services among adult Canadians with chronic back disorders: an observational study. BMC Health Serv Res. 2018; 18: 970.

4. Sutherland DC. The development of chiropractic in the Canadian health care system. JCCA. 1993; 37: 164-176.

5. Geekie DA. CMA's slashing attack on chiropractors. CMAJ. 1972. 107: 73-75.

6. Wilk v. American Medical Association, 895 F.2d 352 (7th Cir. 1990) [Available at: http://www.chiro.org/abstracts/amavschiro.pdf; Accessed 5 February 2021]

7. Greene BR, Smith M, Allareddy V, Haas M. Referral patterns and attitudes of primary care physicians towards chiropractors. BMC Complement Altern Med. 2006; 6: 5.

8. Allareddy V, Greene BR, Smith M, Haas M, Liao J. Facilitators and barriers to improving interprofessional referral relationships between primary care physicians and chiropractors. J Ambul Care Manage. 2007; 30: 347-54.

9. McGregor M, Puhl AA, Reinhart C, Injeyan HS, Soave D. Differentiating intraprofessional attitudes toward paradigms in health care delivery among chiropractic factions: results from a randomly sampled survey. BMC Complement Altern Med. 2014; 14: 51.

10. Blanchette MA, Rivard M, Dionne CE, Cassidy JD. Chiropractors' characteristics associated with physician referrals: results from a survey of Canadian doctors of chiropractic. J Manip Physiol Ther. 2014;38(6):395-406.

11. Meeker WC, Haldeman S. Chiropractic: a profession at the crossroads of mainstream and alternative medicine. Ann Intern Med. 2002 Feb 5;136(3):216-27.

12. Leboeuf-Yde, C., Innes, S.I., Young, K.J. et al. Chiropractic, one big unhappy family: better together or apart? Chiropr Man Therap 27, 4 (2019).

13. Eisenberg DM, Kessler RC, Van Rompay MI, Kaptchuk TJ, Wilkey SA, Appel S, Davis RB. Perceptions among complementary therapies relative to conventional therapies among adults who use both: results from a national survey. Ann Intern Med. 2001; 135: 344-351.

14. Peter Morrison, Adjusting the Role of Chiropractors in the United States: Why Narrowing Chiropractor Scope of Practice Statutes Will Protect Patients, 19 Health Matrix 493 (2009) (Available at: https://scholarlycommons.law.case.edu/healthmatrix/vol19/iss2/21; Accessed 5 February 2021)

15. Cherkin D, MacCornack FA, Berg AO. Family physicians' views of chiropractors: hostile or hospitable? Am J Public Health 1989; 79: 636-7.

16. Greene BR, Smith M, Allareddy V, Haas M. Referral patterns and attitudes of primary care physicians towards chiropractors. BMC Complement Altern Med 2006; 6: 5-15.

17. Marja J Verhoef and Stacey A Page. Physicians' perspectives on chiropractic treatment. JCCA. 1996; 40: 214-9.

18. Reiter HH. Some physicians' perceptions of chiropractors, osteopaths, and podiatrists. Percept Mot Skills. 1965; 20(suppl): 1167-8.

19. King-Isaacs D, Lichti J, Newton-Leo L. Knowledge and opinions of Downsview physicians regarding the chiropractic profession. JCCA. 1994; 38: 90-7. 
20. Griffith LE, Cook DJ, Guyatt GH, Charles CA. Comparison of open and closed questionnaire formats in obtaining demographic information from Canadian general internists. J Clin Epidemiol 1999; 52: 9971005.

21. Scott's Directories (Available at: https://www.scottsdirectories.com/canadian-directories/canadianmedical-directory/; Accessed 5 February 2021)

22. Nakash RA, Hutton JL, Jørstad-Stein EC, et al. Maximising response to postal questionnaires: a systematic review of randomised trials in health research. BMC Med Res Methodol. 2006; 6: 5.

23. Busse JW, Jacobs C, Ngo T, et al. Attitudes toward chiropractic: a survey of North American orthopedic surgeons. Spine (Phila Pa 1976); 34: 2818-25.

24. Weis CA, Cheung G, Dion L, et al. Attitudes towards chiropractic: A survey of Ontario midwives. Podium presentation at the DC 2017. Washington, DC, USA. March 15-18, 2017.

25. Weis CA, Stuber K, Nash J, et al. Attitudes towards chiropractic: A survey of Canadian obstetricians. J Evid Based Complementary Altern Med. 2016; 21: 92-104

26. Harrell FE. Multivariate modeling strategies. In: Harrell FE, ed. Regression Modeling Strategies with Applications to Linear Models, Logistic Regression and Survival Analysis. New York, NY: Springer; 2001:53-85.

27. Belsley DA, Kuh E, Welsch RE: Regression Diagnostics: Identifying Influential Data and Sources of Collinearity. New York, John Wiley \& Sons. 1980.

28. Norman GR, Sloan JA, Wyrwich KW. Interpretation of changes in health related quality of life: the remarkable universality of half a standard deviation. Med Care. 2003; 41: 582-92.

29. Burns KE, Duffett M, Kho ME, et al. A guide for the design and conduct of self-administered surveys of clinicians. CMAJ 2008; 179: 245-52.

30. Canadian Chiropractic Association. Interprofessional Collaboration (Available at: https://chiropractic.ca/about-cca/code-of-ethics/inter-professional-collaboration/; Accessed 5 February 2021)

31. Canadian Chiropractic Association. Advocacy (Available at: https://chiropractic.ca/about-cca/advocacy/; Accessed 5 February 2021)

32. Bronfort, G., Haas, M., Evans, R. Leininger B, Triano J. Effectiveness of manual therapies: the UK evidence report. Chiropr Man Therap. 2010; 18: 3.

33. Huang T, Shu X, Huang YS, Cheuk DK. Complementary and miscellaneous interventions for nocturnal enuresis in children. Cochrane Database Syst Rev. 2011; 12: CD005230.

34. Hondras MA, Linde K, Jones AP. Manual therapy for asthma. Cochrane Database Syst Rev. 2005; 2: CD001002.

35. Pierre Côté, Jan Hartvigsen, Iben Axén, et al. The Global Summit on the Efficacy and Effectiveness of Spinal Manipulative Therapy for the Prevention and Treatment of Non-musculoskeletal Disorders: A Systematic Review of the Literature. Accepted for publication in Chiropractic \& Manual Therapies.

36. Paige NM, Miake-Lye IM, Booth MS, et al. Association of Spinal Manipulative Therapy with Clinical Benefit and Harm for Acute Low Back Pain: Systematic Review and Meta-analysis. JAMA. 2017; 317: $1451-1460$. 
37. Rubinstein SM, de Zoete A, van Middelkoop M, et al. Benefits and harms of spinal manipulative therapy for the treatment of chronic low back pain: systematic review and meta-analysis of randomised controlled trials. BMJ. 2019; 364: 1689.

38. Masaracchio M, Kirker K, States R, Hanney WJ, Liu X, Kolber M. Thoracic spine manipulation for the management of mechanical neck pain: A systematic review and meta-analysis. PLoS One. 2019; 14: e0211877.

39. Shekelle PG, Paige NM, Miake-Lye IM, Beroes JM, Booth MS, Shanman R. The Effectiveness and Harms of Spinal Manipulative Therapy for the Treatment of Acute Neck and Lower Back Pain: A Systematic Review [Internet]. Washington (DC): Department of Veterans Affairs (US); 2017 Apr. PMID: 28704021.

40. Fernandez M, Moore C, Tan J, Lian D, Nguyen J, Bacon A, Christie B, Shen I, Waldie T, Simonet D, Bussières A. Spinal manipulation for the management of cervicogenic headache: A systematic review and meta-analysis. Eur J Pain. 2020; 24: 1687-1702.

41. Kolber MR, Ton J, Thomas B, Kirkwood J, Moe S, Dugré N, Chan K, Lindblad AJ, McCormack J, Garrison S, Allan GM, Korownyk CS, Craig R, Sept L, Rouble AN, Perry D. PEER systematic review of randomized controlled trials: Management of chronic low back pain in primary care. Can Fam Physician. 2021; 67: e20-e30.

42. National Institute for Health and Care Excellence (NICE). Low back pain and sciatica in over 16s: assessment and management. NICE guideline [NG59]. London (UK): NICE; 2016.

43. Qaseem A, Wilt TJ, McLean RM, et al. Clinical Guidelines Committee of the American College of Physicians. Non-invasive treatments for acute, subacute, and chronic low back pain: a clinical practice guideline from the American College of Physicians. Ann Intern Med 2017; 166: 514-30.

44. North American Spine Society. Evidence-Based Clinical Guidelines for Multidisciplinary Spine Care: Diagnosis \& Treatment of Low Back Pain. 2020 (available at: https://www.spine.org/Portals/0/assets/downloads/ResearchClinicalCare/Guidelines/LowBackPain.pdf; Accessed 5 February 2021)

45. Ernst E. Deaths after chiropractic: a review of published cases. Int J Clin Pract. 2010; 64: 1162-5.

46. Cassidy JD, Boyle E, Côté P, Hogg-Johnson S, Bondy SJ, Haldeman S. Risk of Carotid Stroke after Chiropractic Care: A Population-Based Case-Crossover Study. J Stroke Cerebrovasc Dis. 2017; 26: 842850.

47. Cassidy JD, Boyle E, Côté P, He Y, Hogg-Johnson S, Silver FL, Bondy SJ. Risk of vertebrobasilar stroke and chiropractic care: results of a population-based case-control and case-crossover study. Spine (Phila Pa 1976). 2008; 33(4 Suppl): S176-83.

48. Boyle E, Côté P, Grier AR, Cassidy JD. Examining vertebrobasilar artery stroke in two Canadian provinces. Spine (Phila Pa 1976). 2008; 33(4 Suppl): S170-5.

49. Ernst E. Manipulation of the cervical spine: a systematic review of case reports of serious adverse events, 1995-2001. Med J Aust 2002; 176: 376-80.

50. Rothwell DM, Bondy SJ, Williams JI. Chiropractic manipulation and stroke: a population-based casecontrol study. Stroke 2001; 32: 1054-60. 
51. Smith WS, Johnston SC, Skalabrin EJ, et al. Spinal manipulative therapy is an independent risk factor for vertebral artery dissection. Neurology 2003; 60: 1424-8.

52. Arnold M, Bousser M. Clinical manifestations of vertebral artery dissection. Front Neurol Neurosci. 2005; 20:77-86.

53. Moser N, Mior S, Noseworthy M, Côté P, Wells G, Behr M, Triano J. Effect of cervical manipulation on vertebral artery and cerebral haemodynamics in patients with chronic neck pain: a crossover randomised controlled trial. BMJ Open. 2019; 9: e025219.

54. Futch D, Schneider MJ, Murphy D, Grayev A. Vertebral artery dissection in evolution found during chiropractic examination. BMJ Case Rep. 2015; 2015: bcr2015212568.

55. Finley CR, Chan DS, Garrison S, Korownyk C, Kolber MR, Campbell S, Eurich DT, Lindblad AJ, Vandermeer B, Allan GM. What are the most common conditions in primary care? Systematic review. Can Fam Physician. 2018; 64: 832-840.

56. Shekelle PG, Coulter I, Hurwitz EL, Genovese B, Adams AH, Mior SA, Brook RH. Congruence between decisions to initiate chiropractic spinal manipulation for low back pain and appropriateness criteria in North America. Ann Intern Med 1998; 129: 9-17.

57. Grod JP, Sikorski D, Keating JC Jr. Unsubstantiated claims in patient brochures from the largest state, provincial, and national chiropractic associations and research agencies. J Manipulative Physiol Ther 2001; 24: 514-9.

58. Herman PM, Vernon H, Hurwitz EL, Shekelle PG, Whitley MD, Coulter ID. Clinical Scenarios for Which Cervical Mobilization and Manipulation Are Considered by an Expert Panel to Be Appropriate (and Inappropriate) for Patients With Chronic Neck Pain. Clin J Pain. 2020; 36: 273-280.

59. The Canadian Chiropractic Guideline Initiative. (Available at: https://www.ccgi-research.com/; Accessed 5 February 2021)

60. Wand BM, Heine PJ, O'Connell NE. Should we abandon cervical spine manipulation for mechanical neck pain? Yes. BMJ. 2012; 344: e3679.

61. Cassidy JD, Bronfort G, Hartvigsen J. Should we abandon cervical spine manipulation for mechanical neck pain? No. BMJ. 2012; 344: e3680.

62. Pascucci D, Sassano M, Nurchis MC, Cicconi M, Acampora A, Park D, Morano C, Damiani G. Impact of interprofessional collaboration on chronic disease management: Findings from a systematic review of clinical trial and meta-analysis. Health Policy. 2021; 125: 191-202.

63. Lutfiyya MN, Chang LF, McGrath C, Dana C, Lipsky MS. The state of the science of interprofessional collaborative practice: A scoping review of the patient health-related outcomes based literature published between 2010 and 2018. PLoS One. 2019; 14: e0218578.

64. Mior S, Gamble B, Barnsley J, Côté P, Côté E. Changes in primary care physician's management of low back pain in a model of interprofessional collaborative care: an uncontrolled before-after study. Chiropr Man Therap. 2013; 21: 6.

65. Zarrabian M, Bidos A, Fanti C, Young B, Drew B, Puskas D, Rampersaud R. Improving spine surgical access, appropriateness and efficiency in metropolitan, urban and rural settings. Can J Surg. 2017; 60: 342-348. 
66. Spaulding EM, Marvel FA, Jacob E, Rahman A, Hansen BR, Hanyok LA, Martin SS, Han HR. Interprofessional education and collaboration among healthcare students and professionals: a systematic review and call for action. J Interprof Care. 2019: 1-10.

67. Nguyen J, Smith L, Hunter J, Harnett JE. Conventional and Complementary Medicine Health Care Practitioners' Perspectives on Interprofessional Communication: A Qualitative Rapid Review. Medicina (Kaunas). 2019; 55: 650.

\section{Supplementary Files}

This is a list of supplementary files associated with this preprint. Click to download.

- SupplementaryFileFeb92021.docx 